\title{
Knowledge and practices among registered nurses on occupational hazards in Onandjokwe Health District: Oshikoto region, Namibia
}

\author{
Julia Amadhila, Jacoba Marieta Van der Vyver, Daniel Opotamutale Ashipala* \\ Department of General Nursing Science, School of Nursing, Faculty of Health Sciences, University of Namibia (UNAM), Namibia
}

Received: May 11, 2017

DOI: $10.5430 /$ jha.v6n4p46
Accepted: July 10, 2017

URL: https://doi.org/10.5430/jha.v6n4p46

\begin{abstract}
Objective: This study sought to explore and describe the extent of the knowledge on occupational hazards amongst registered nurses in Onandjokwe Health District.

Methods: This study used a quantitative research design utilizing a survey by means of a questionnaire. The population of the study consisted of randomly selected registered nurses who were in direct contact with patients. Data was gathered using questionnaires, utilized for descriptive statistics and evaluated with quantitative, computerised statistical techniques using. Statistical Package for the Social Scientists (SPSS).

Results: The findings of this study revealed that the majority of registered nurses have knowledge on occupational hazards, yet a few number $(24 \%)$ have insufficient knowledge. The findings also revealed that information and support is provided to some (22\%) nurses.

Recommendations: Recommendations made based on the findings of this study include regular training and educational meetings to enhance occupational safety, develop/introduce policies and guidelines or strategies on all aspects related to occupational hazards/safety.

Conclusions: Most (76\%) of the registered nurses have knowledge on the ways that they can be exposed to occupational hazards in the following areas: such as handling of sharp instruments, lifting of patients, exposure to psychological problems due to frustrations, and exposure airborne diseases.
\end{abstract}

Key Words: Knowledge, Practices, Occupational therapy, Hazards, Exposure

\section{INTRODUCTION}

Occupational health practice is originally from Europe following the systematic work of Bernadino Ramazzini in Italy at the turn of the $17^{\text {th }}$ century ${ }^{[1]}$ occupational health and safety maintains and enhances employee health, improve safety and increase productivity in the workplace. Therefore it promotes and maintains the highest degree of physical, mental and well-being of workers in the occupations by con- trolling risks. ${ }^{[2]}$

Effective occupational health benefits the employee, employer, government and the society at large. The employee is benefiting by being able to work in a state of physical, mental, social and spiritual well-being without occupational hazards. An unsafe workplace may lead to high turnover of workers which leads to more employer financial losses in recruiting more workers and loss of skills. These loses are min-

\footnotetext{
*Correspondence: Daniel Opotamutale Ashipala; Email: dashipala@unam.na; Address: School of Nursing, Faculty of Health Sciences, University of Namibia (UNAM), P.O.Box 88, Rundu, Namibia.
} 
imized by promoting occupational safety and health. Nursing is a profession that is overwhelmingly concerned with the care of others and it tends to neglect itself. Work-related injuries impact the health care organization by increasing costs through medical expenses, loss of working days as well as reduced ability to provide services by the workers. ${ }^{[3]}$ Nursing personnel face a wide range of workplace hazards exposure than other health care workers because of the nature of nursing responsibilities involving 24 interactions care of patients, performing invasive procedures such as positioning/turning/walking patients, etc. ${ }^{[4]}$

Occupational hazards include physical, mechanical, biological and psychological hazards. Biological hazards are mainly infectious hazards such as bacteria, viruses, fungi and parasites, which cause diseases such as HIV/AIDS, tuberculosis, hepatitis and other blood borne infections. ${ }^{[2]}$ Physical hazards commonly found in health facilities include radiation, exposure to slippery floors, exposure to body fluids and assault by confused patients. Mechanical hazard include back pain/injury due to manual lifting of patients. This is the main (support vague claim) and a common hazard in hospitals and health centers whereby lifting, turning, moving and adjusting beds by hand are routine activity of daily work. ${ }^{[5]}$

\subsection{Problem statement}

Despite the efforts of the Ministry of Health and Social Services (MoHSS) in 2012 to develop guidelines and policies for the management of occupational hazards in the workplace, there is evidence that nurses are exposed to many occupational hazards and it seems that there is a lack of information on the causes, prevention and management of occupational injuries/illnesses. It is also not clear whether nurses in Onandjokwe Lutheran Medical Hospital practice occupational safety and whether there are strategies in place dealing preventing occupational safety/hazards. The above phenomenon has led to the formulation of the research question: To what extent, do registered nurses have knowledge on and practice occupational hazards/safety in Onandjokwe Health District? The researcher is not aware of any research conducted investigating the knowledge and practices among registered nurses on occupational hazards in Onandjokwe health district.

\subsection{Aim of the study}

The purpose of the study was to determine the existing knowledge and practices of the registered nurses on occupational hazard and safety in the Onandjokwe health district.

\subsection{Research objectives}

The objectives of the study were:

Published by Sciedu Press
- To determine the extent of the knowledge on occupational hazards amongst registered nurses in the Onandjokwe Health District.

- To determine the extent to which registered nurses practice occupational safety in Onandjokwe Health District.

\subsection{Significance of the study}

A study of this nature might improve knowledge and practice on issues pertaining to occupational health and safety in the Onandjokwe health district. It might also help to contribute towards nursing research in Namibia through new knowledge that will be generated. This study might lead to health improvement of the nursing personnel by using new knowledge gained from the study. As a result the quality of nursing care will be improved because a health care provider will result in improved patient care.

\section{RESEARCH METHOD AND DESIGN}

The study used a non-experimental research design using a quantitative exploratory descriptive design. A research design is necessary to translate the research objectives into measurable and valid information that informs this study. ${ }^{[6]}$

\subsection{Population}

The population in this study included all the registered nurses who were directly involved with patient care in the district. Included in the sample are randomly drawn from those nurses from Onandijokwe facilities that include health centers and clinics who perform bedside nursing care in the wards and those who do the screening and administration of treatment in the clinics.

\subsection{Sampling and sample size}

A simple random sampling was used to draw $50 \%$ of the total registered nurses in Onandjokwe Health District. In this study a lottery technique was used, whereby a list of all the registered nurses was obtained, and names were placed in a container mixed well and then names were drawn that constituted the sample. ${ }^{[6]}$ Onandjokwe Health District has a total number of 115 registered nurses. Registered nurses were the target population of this study.

Sample was selected as follows (see Table 1):

Most of the sample $41(82 \%)$ was taken from the hospital because it has a large number of registered nurses in the district while some clinics do not have registered nurses.

\subsection{Validity and liability}

The researcher paid attention to the selection of the sample and data collection criteria, so that the results of the study can 
be valuable. This was achieved through random selection of exclusively registered nurse for this study. In order to ensure face validity, a study supervisor and experts were utilized to review the questionnaire prior to distribution and included experienced registered nurse (39), a doctor and an infection control specialist reviewed.

Table 1. Sample size

\begin{tabular}{ll}
\hline Name of Health Facility & Number of Registered Nurses \\
\hline Onandjokwe Hospital & 41 \\
Health Centers & 3 \\
Clinics & 6 \\
Total & 50 \\
\hline
\end{tabular}

An ordinal rating scale was compiled and distributed to experts in the two hospitals for comments, which are Onandjokwe and Oshakati Hospitals respectively, assessing the content validity of the instrument. A panel of ten (10) experts rated the items on the scale of one to four: (1) irrelevant, (2) remove as not relevant (3) relevant, and (4) specifically critical due to the intent of the study. The researcher revised the instrument based on feedback from the experts. The researcher ensured reliability by explaining the questions in language easily understood, as rated as clear by the reviewers, the purpose of the study to the respondents. Questionnaires were written in simple language and explanations of questions were offered to the respondents. A pilot study was also conducted.

\subsection{Data analysis}

Descriptive statistics were gathered from the survey. These statistics and the data related to survey tool were evaluated with quantitative, computerised statistical techniques, using SPSS. To evaluate the data, the researcher enlisted the assistance of a professional statistician.

\subsection{Ethical consideration}

Permission to conduct the study was requested and granted from the following:

The University of Namibia - Research and Publication Office (RPO) for ethical review and approval purposes. The Ministry of Health and Social Services research unit for the approval of the research protocol. Free choice of participation was allowed without prejudice anybody. Confidentiality and anonymity were ensured, whereby respondents were not allowed to reveal names and addresses on the questionnaires. Furthermore, the researcher did not divulge the information without permission.

\section{RESUltS}

\subsection{Introduction}

The data were analyzed and interpreted according to the items in the questionnaire. The total number of 50 questionnaires that were distributed and returned contributed to the research findings. All the fifty (50) returned questionnaires were analyzed under the headings as well as subheadings of the questions.

\subsection{Sociodemographic characteristics of the respon- dents}

\subsubsection{Age in years}

The age of the respondents ranged from 20 to 59 years old. The majority of the respondents, 17 (34\%) of the sample, were in the age category of 30-39 years. Fifteen (15) respondents $(30 \%)$ were between 50 to 59 years old, while fifteen (15) respondents $(30 \%)$ were $40-49$ years old. The remaining three (3) $6 \%$ respondents of the sample were in the age range of 20-29 years (see Table 2).

Table 2. Age in years

\begin{tabular}{cll}
\hline Age & Frequency & Percentage \\
\hline$\bullet 20-29$ & 3 & 6.0 \\
$\bullet 30-39$ & 17 & 34.0 \\
$\bullet 40-49$ & 15 & 30.0 \\
$\bullet 50-59$ & 15 & 30.0 \\
Total & 50 & 100.0 \\
\hline
\end{tabular}

\subsubsection{Gender}

The nursing profession is predominantly a female profession as it will be indicated below: The total numbers of $41(82 \%)$ respondents were females whereas $6(12 \%)$ of the sample were males. Three (3) respondents which are $6 \%$ of the sample did not indicate their sex (see Table 3).

Table 3. Gender

\begin{tabular}{lcc}
\hline Sex & Frequency & Percentage \\
\hline$\bullet$ Female & 41 & 82.0 \\
$\bullet$ Male & 6 & 12.0 \\
Total & 47 & 94.0 \\
Missing/No answer & 3 & 6.0 \\
Total & 50 & 100.0 \\
\hline
\end{tabular}

\subsubsection{Years of experience as a registered nurse}

The majority of the respondents have worked for 6 years and more as registered nurses. That is indicated as follows: Seventeen (17) or 34\% respondents worked for 6-10 years as registered nurses. The range of 11-20 years was presented by $13(26 \%)$ respondents. Eleven (11) $22 \%$ respondents have worked for more than 20 years as registered nurses. Only nine $(18 \%)$ of the sample who have the experience less than

ISSN 1927-6990 E-ISSN 1927-7008 
five years as registered nurses. This indicates that a majority or $82 \%$ of the respondents had 5 or more years of experience in nursing as registered nurses (see Table 4).

Table 4. Years of experience as a registered nurse

\begin{tabular}{cll}
\hline Years of Experience & Frequency & Percentage \\
\hline - Less than 5 & 9 & 18.0 \\
- $6-10$ & 17 & 34.0 \\
- $11-20$ & 13 & 26.0 \\
- More than 20 & 11 & 22.0 \\
Total & 50 & 100.0 \\
\hline
\end{tabular}

\subsection{Knowledge on occupational hazards}

\subsubsection{Understanding of occupational hazards}

Occupational hazards are risks/dangers accepted as consequences of a particular occupation. ${ }^{[7]}$ These can be injuries/illnesses/diseases to which health workers are exposed to while on duty and can result in either short or long-term injuries/illnesses/diseases. The majority of the respondents, that is $39(76 \%)$ of the sample, understood occupational hazards indicated in their responses. Three $6 \%$ of these 39 respondents have extensively explained occupational hazards, that it can be physical, mental and spiritual injury/illness while on duty and that may occur due to lack of skills or lack of abilities (see Tables 5 and 6).

Table 5. Needle-stick injuries' procedures awareness

\begin{tabular}{cll}
\hline Responses & Frequency & Percentage \\
\hline$\bullet$ Yes & 48 & 96.0 \\
$\bullet$ No & 2 & 4.0 \\
Total & 50 & 100.0 \\
\hline
\end{tabular}

Table 6. Guidelines on body mechanics

\begin{tabular}{cll}
\hline Responses & Frequency & Percentage \\
\hline$\bullet$ Yes & 18 & 36.0 \\
$\bullet$ No & 32 & 64.0 \\
Total & 50 & 100.0 \\
\hline
\end{tabular}

\subsubsection{Immunization status against Hepatitis $B$}

Exposure to Hepatitis B is one of the serious occupational risks that a nurse may get as a blood borne disease. Nurses need to be protected from these preventable diseases. According to the health belief model, health workers would be able to prevent occupational hazards if they believe that those hazards have serious consequences such as disability, death and social effects in life or work. ${ }^{[8]}$ Twenty-two (44\%) respondents indicated that they have received immunization against Hepatitis B, while alarming (56\%) respondents have not received any vaccine against Hepatitis B (see Figure 1). A variety of reasons for being immunized may support these figures.

Published by Sciedu Press

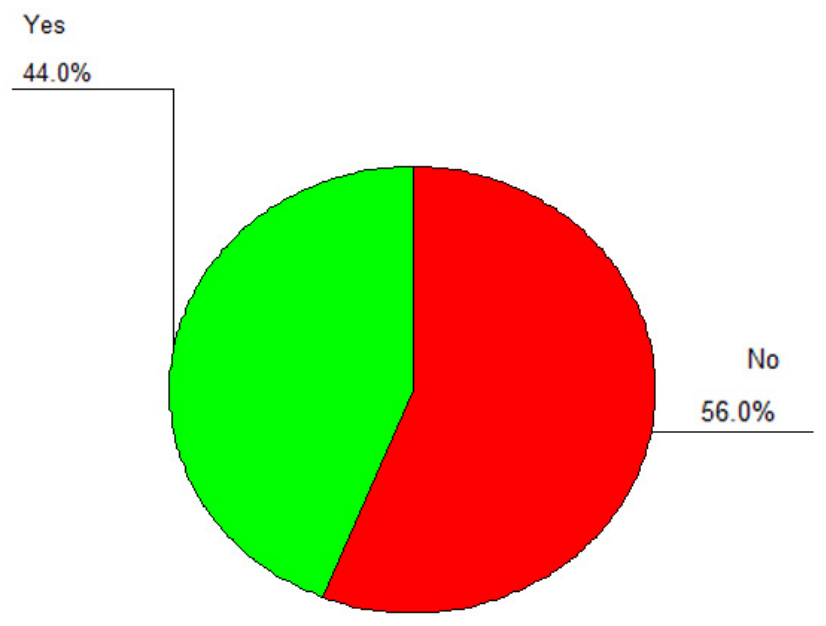

Figure 1. Received immunization against Hepatitis B

\subsubsection{Reasons for being immunized against Hepatitis $B$}

Fourteen $(28 \%)$ respondents indicated that they were immunized against Hepatitis B because they were exposed to caring patients who were diagnosed with Hepatitis B. ${ }^{[8]}$ indicated that health workers would be able to prevent occupational hazards if there is perceived threat of the disease. Nurses are threatened by those fatal occupational diseases.

3.4 Responses as to whether any other prophylactic treatment against infectious diseases was received

Twenty-two (44\%) respondents indicated that they have received other prophylactic treatment. Twenty-eight (56\%) indicated that they have never received any other prophylactic treatments (see Figure 2).

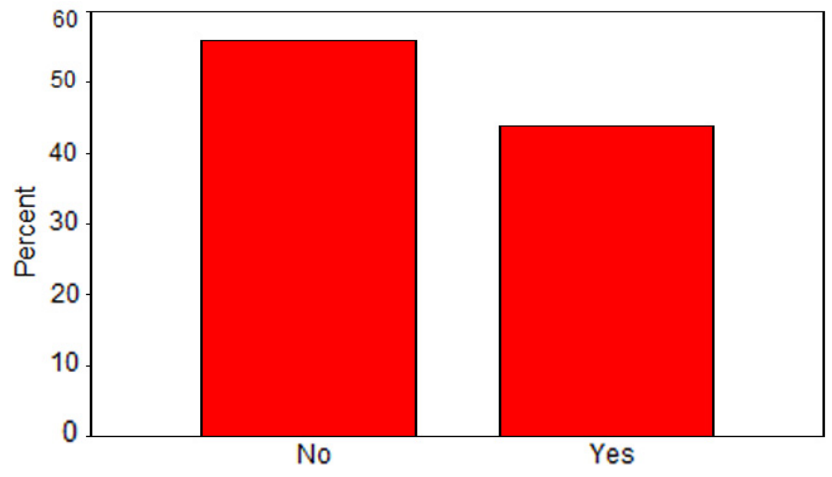

Figure 2. Received any other prophylactic treatment

\subsubsection{Responses on the other type of prophylactic treat- ment received against infectious diseases and the reasons for receiving it}

Sixteen $(32 \%)$ responded that they have received prophylactic treatments against meningitis. That include: meningococcal vaccine. One (2\%) respondent among those above added that she received a flu-vaccine due to recurrent attack. Three 
$(6 \%)$ indicated that they have received a prophylaxis against HIV/AIDS. It was indicated that on the case of needle-prick injury, the patient was tested HIV positive. The remaining three $(6 \%)$ responded that they have received prophylaxis against the following diseases respectively: plague and rabies. The number of reported prophylactic treatments are an indication that nurses in the obstetric unit are highly exposed to blood borne diseases because their work exposed them extensively.

\subsection{Practices on occupational hazards}

With regard to handling of used needles and sharp instruments, $90 \%$ of the registered nurses indicated that these should be disposed directly after use into a waterproof safety box container for sharps. Only $2 \%$ of the registered nurses felt that needles should be disposed after recapping. Among the respondents $(44 \%)$ registered nurses revealed that they received Hepatitis B immunization as a prophylaxis and routine measure in their departments. Eight-four (84\%) registered nurses expressed that they give particular attention to the correct body mechanics when lifting, turning or getting up weak patients, while $8 \%$ did not do. All respondents (100\%) indicated that they wash their hands on duty to prevent or reduce cross infections. Ninety-six (96\%) of the respondents indicated that they use gloves, aprons, face masks and goggles during surgeries or when performing procedures.

\section{DISCUSSION}

It became evident that in Onandjokwe Health District the majority of registered nurses $(88 \%)$ have knowledge on occupational hazards, types of risks that expose nurses to injuries on duty, preventive measures and procedures to be followed in case if injury on duty occurs. However, there were still few $(12 \%)$ respondents who did not understand occupational hazards and safety. Ninety percent $(90 \%)$ of the respondents also indicated that the knowledge that they have on occupational hazard and safety, is cultivated into practice. That was indicated when most of the registered nurses indicated that they follow guidelines on: handling of used needles/sharps, exposure to Hepatitis B/other communicable infections, hand wash, protective measures and moving weak patients. Those are some of the prevalent causes for nurses' exposures to risks.

Nevertheless, a restriction is one of the identified barriers that prevent all the nurses to practice occupational safety. It was also indicated that there are some guidelines in place to deal with occupational hazards. However, some registered nurses stated that no information is provided to them and no support is given when one is suffering from an injury on duty.

\section{Conclusions}

It was evident that a significant number of registered nurses have knowledge on occupational hazards. This was indicated in the study by extensive definitions of occupational hazards that it is physical and mental illness which they face while on duty. It can also be concluded from the responses from this study sample that most of the registered nurses have knowledge on the ways that they can be exposed to occupational hazards such as handling of sharp instruments, lifting of patients and exposure to exposure to airborne diseases. However, the findings revealed that only six (12\%) registered nurses who could not explain occupational hazards. This might be indicative of the inability to express themselves in English or of ignorance. Most of the registered nurses indicated that they know the preventive measures as well as the procedures to be followed in cases of injury on duty.

\section{Recommendations}

The following recommendations are made based on the findings of this study:

- Policies, guidelines, enough booklets/leaflets and pamphlets/posters regarding occupational hazards and safety should be provided and distributed to all the units/departments, so that every nurse will be able to read.

- Provision of leaflets and pamphlets on occupational hazards/safety should also be done in local languages to ensure that the message is clear to every nurse.

- Unit supervisors should strengthen the effective communication regarding occupational hazards and safety to the subordinates in the wards. This can be done through in-service training, mass meetings and workshops.

- Media such as televisions and radios should be used to inform the public on issues related occupational hazards and safety.

- Provision of support in case of occupational injury or illness should be equally rendered to all the nurses.

- Additional guidelines related to occupational hazards and safety should be introduced.

\section{ACKNOWLEDGEMENTS}

We thank all the respondents who took time to participate in this study; without their participation this study would not have been a success or even possible. We also thank the Ministry of Health and Social Services for having granted us permission to conduct research in its health facilities. The authors contributed as follows: Julia Amadhila is the principal investigator, Marieta van der vyver, supervised the project and Daniel Opotamutale Ashipala wrote the manuscript. 


\section{CONFlicts of InTERest Disclosure}

The authors declare they have no conflict of interest.

\section{REFERENCES}

[1] Orji EO, Fasubaa OB, Onwudiegwu U, et al. 2002. Occupational health hazards among health care workers in an obstetrics and gynecology unit of a Nigerian teaching hospital. Journal of Obstetrics and Gynecology. 2002; 22(1): 75-78. PMid: 12521735. https://doi.org/10.1080/01443610120101781

[2] Occupational Health center. Workplace hazards: 4 Common types. The center for disease control and prevention. 2016.

[3] Ghosh T. Occupational Health and hazards among Health care Workers. International Journal of occupational Safety and Health. 2013; 3(1): 1-4. https://doi.org/10.3126/ijosh.v3i1.9096

[4] Amukugo HJ, Amakali K, Sipa K. Perception of health workers regarding the occupational health services rendered at Onandjokwe hospital, Namibia. Journal of Hospital Administration. 2015; 4(6): 1-13.

[5] Ndejjo R, Musinguzi G, Yu X, et al. Occupational Health Hazards among Healthcare Workers in Kampala, Uganda. Journal of Environmental and Public Health. 2015; 2015.

[6] Brink H, Van der Walt C, Van Rensburg G. Fundamentals of Research methodology for health professionals. $2^{\text {nd }}$ edition. Cape Town. South Africa: Juta \& Company Ltd; 2012.

[7] Wehmeier S. Oxford Advanced Learners' Dictionary of Current English. New York: Oxford University Press; 2000.

[8] Glanz K, Rimer BK, Viswanath K, et al. Health behavior and health education: Theory, research, and practice. San Francisco, CA: JosseyBass; 2008. 